\title{
Influences of TIG welding parameters on tensile and impact behaviour of aluminium alloy joints: A Review
}

\author{
Yashwant Thakur ${ }^{1}$, Khushmeet Kumar ${ }^{2}$, Krishan Kumar ${ }^{3}$ \\ ${ }^{1,2,3}$ (Department of Mechanical Engineering, School of Engineering \& Emerging Technologies, Baddi \\ University of Emerging Sciences and Technology, Baddi, H.P, India)
}

\begin{abstract}
Aluminium is a non-magnetic, silvery-white, ductile and soft metal which is the most abundant metal and the third most abundant element in the earth crust. It also makes its existence in the form of its alloys in which aluminium is predominant metal. Copper, magnesium, manganese, silicon, tin and zinc are the typical alloying metals. Aluminium alloys are widely used in engineering structure, components and aerospace manufacturing where light weight and corrosion resistance is required. TIG welding is a precise and fastest welding technique able to weld ferrous and non-ferrous metals. It is highly controllable, fumeless and spatter less clean process needs very little finishing or sometime no finishing. The present work deals with the identification of best combination of welding parameters for TIG welding of AA7005. From the literature survey, it is found that welding of aluminium is very difficult with conventional arc welding processes. There are no. of welding parameters which affect the welding quality for again repeatability. Different parameteric ranges \& their effects are studied. In this particular study, TIG welding set up will be used to weld 10mm thick AA7005 plate by changing the welding parameters. The effect of these parameters on tensile and impact strength of welding joints will be analyzed.
\end{abstract}

Keywords- TIG welding, AA7005, Welding current, Gas flow rate, Welding speed, Tensile strength, Impact strength.

\section{INTRODUCTION}

Welding is a permanent fastening process used to join different ferrous and non ferrous materials like metals and alloys at their contacting surfaces by application of heat and or pressure. It is one of the mostly used welding process for aluminium and its alloys [1]. The work-pieces to be joined are melted at the interface and after solidification a permanent joint can be achieved. Sometimes a filler material is added to form a weld pool of molten material which after solidification gives a strong bond between the materials. Weld ability of a material depends on melting point of metal, thermal conductivity, reactivity, thermal expansion of metals, electrical resistance and surface conditions.

\subsection{TIG Welding}

An arc welding process used to weld material with a non consumable tungsten electrode. The electrode is connected to a required power source and shielding gas is also employed through welding gun [2]. Generally Argon or Helium is used as shielding gas to protect welding surface from atmosphere. The application of filler metal is optional depends upon the kind of weld or requirement. TIG welding helps in welding of difficult to weld materials like aluminium and Magnesium. The applications of TIG welding nowadays has been expanded to variety of metas like MS, SS, HSS etc. Tungsten Inert Gas (TIG) welding is used for variety of materials to give high quality welding with the coalescence of heat generated by an electric arc established between a tungsten electrode and the metal [3]. The electrode is non-consumable. The process give rise to the formation of fumes and gases while melting the work piece and filler rod to form a weld. Helium and argon are specially used as shielding gases because they does not chemically react. The inert gas i) protect the welding area from air, prevent oxidation, ii) transfers the heat during welding iii) helps to start and maintain a stable arc due to low ionization potential [4]. 


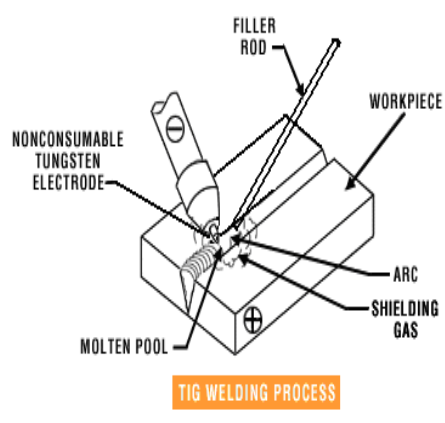

Fig.1 Schematic diagram of TIG welding

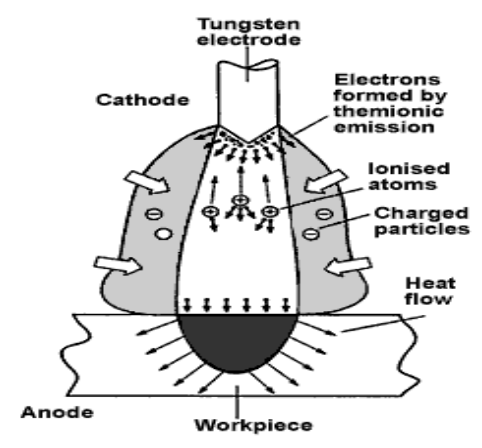

Fig.2 Mechanism of TIG welding

\subsection{Welding Of Aluminum Alloys}

Many industries which are involved in transportation like automobile industries primarily concerned on reduction of mass, which has become quite useful because of fuel saving, reduction of emission and recyclability. Hence it has become more predominant to focus on light weight materials like aluminium and magnesium [5][6]. Thermal conductivity of aluminum is quite high; therefore heat is easily conducted away from the welding area. It is quite essential for a heat source to reach rapidly at aluminum's melting point of 565 $1650^{\circ} \mathrm{C}$ [7]. Coefficient of thermal expansion of aluminum is also high compared to steel, so it is prone to distortion and stress inducement if the proper welding procedure is not followed. Aluminum is a reactive metal that quickly forms an oxide layer on the surface and strength of the weld area become weak [8]. Therefore welding of aluminum by conventional arc welding process is become difficult. By understanding the welding characteristics and utilizing proper procedures aluminum and its alloys could be easily weld. The most common commercial aluminum and aluminum alloy welding methods use DC current, with and without pulsed current or a permanent tungsten electrode with AC current [9][10].

TIG welding is commonly used for welding aluminium and aluminium alloys. In this study aluminium alloy 7005 is selected as the base material, it comes under aluminium 7xxx series. AA7005 is a merely alloy of this series with good weldability and can be TIG welded without causing cracks and poor strength joints. Unlike other AA7xxx, it do not contain $\mathrm{Cu}$ in its composition which reduces its ductility and corrosion resistance. Hence susceptibility to solidification cracking of aluminium-copper alloys is increased. Zinc and Magnesium are the most widely used alloying elements for aluminium. AA7005 possess good welding characteristics and resistance to corrosion. The physical properties of AA7005 are similar, except higher density of $2.78 \mathrm{~g} / \mathrm{cm}^{3}$ than AA6061 alloy and may be little stronger depending on the temper. Unlike 6061, It does not need to be precipitation hardened, but can be aired cooled. These alloys are used primarily for bicycle frames, due to its relative ease of welding it is extensively used in defence, aerospace and marine applications due to its high strength.

The properties of AA7005 are given below in TABLE I, TABLE II and TABLE III as shown:

TABLE I. CHEMICAL COMPOSITION OF AA7005

\begin{tabular}{|c|c|c|c|c|c|c|}
\hline Al & Mn & Mg & Cr & Zn & Ti & Zr \\
\hline $93.3 \%$ & $.45 \%$ & $1.4 \%$ & $.13 \%$ & $4.5 \%$ & $.04 \%$ & $.14 \%$ \\
\hline
\end{tabular}

TABLE II. PHYSICAL PROPERTIES OF AA7005

\begin{tabular}{|c|c|c|c|c|}
\hline Phase & $\begin{array}{c}\text { Atomic } \\
\text { Weight }\end{array}$ & Melting Point & Boiling Point & Density \\
\hline Solid & $26.9 \mathrm{AMU}$ & $630^{\circ} \mathrm{C}$ & $2470^{\circ} \mathrm{C}$ & $2.78 \mathrm{gm} / \mathrm{cm}^{3}$ \\
\hline
\end{tabular}


TABLE III. MECHANICAL PROPERTIES OF AA7005

\begin{tabular}{|l|c|c|}
\hline PROPERTIES & VALUE & CONDITION \\
\hline Poisson's Ratio & $2.6-2.8$ & $25^{\circ} \mathrm{C}$ \\
\hline Elastic Modulus (GPa) & $70-80$ & $25^{\circ} \mathrm{C}$ \\
\hline Tensile Strength (MPa) & 193 & $25^{\circ} \mathrm{C}$ \\
\hline Yield Strength (MPa) & 83 & $25^{\circ} \mathrm{C}$ \\
\hline Elongation (\%) & 20 & $25^{\circ} \mathrm{C}$ \\
\hline Shear Strength (MPa) & 140 & $25^{\circ} \mathrm{C}$ \\
\hline
\end{tabular}

\section{LITERATURE REVIEW}

TIG welding is highly precise and clean welding process yet the control and execution of different welding parameters is quite necessary for successful outcome. The different welding parameters are selected by the operator based on his experience or from literature survey. It is not always necessary that the selection of parameters can be optimal and will give same set of result for particular welding environment. In this study, a literature review has been made and attempt has been made to analyze the effect of different parameters on the welding geometry.

Palani PK, Saju M[1] investigated the effect of TIG welding process parameters on welding of Aluminium-65032. Response Surface Methodology was used to conduct the experiments. The parameters selected for controlling the process are welding speed (150-200) $\mathrm{mm} / \mathrm{min}$, current (100-120) A and gas flow rate (10-12) Lit/min. Strength of welded joints were tested by a UTM. Percent elongation was also calculated to evaluate the ductility of the welded joint. From the results of the experiments, mathematical models have been developed to study the effect of process parameters on tensile strength and percent elongation.

Indira Rani [2] performed an investigation on the mechanical properties of TIG welded aluminum alloy.A plate dimension $(300 \times 150 \times 6) \mathrm{mm}$ was taken for the experimentation. Welding parameters was current as (70-74) A, arc travel speed (700-760) $\mathrm{mm} / \mathrm{min}$, and pulse frequency 3 and $7 \mathrm{~Hz}$. It was concluded from the experiment that tensile strength and yield strength of the welded joint was closer to the base metal. Failure of the joint took place at heat affected zone which results that weldments have better weld joint strength.

N.Karunakaran[3] did an investigation to compare the mechanical properties and weiding profiles of TIG welded aluminium alloy joints. The effects of pulsed current on tensile strength, hardness, microstructure and stress distribution were reported. In this investigation, Aluminium plates of dimensions (150x150x4) mm were used. The parameters were welding current (55-75) A. voltage (11-13.5) V and a constant welding speed were used. From the experiment it is found that pulsed welding current improve the tensile behaviour of the weld compared with continuous current welding due to grain refinement occurring in the fusion zone.

S T Kumar, V Balasubramanian, MY Sanavullah [4] studied medium strength aluminium alloy to check its tensile characterstics of AA 6061. Different combinations of welding parameters have been tested on $3 \mathrm{~mm}$ thick plate of aluminium alloy. Peak current, base current, pulse frequency and pulse ON time have been taken as variable parameters. From the results, it has been found that the current and frequency have been directly affecting the tensile properties of the welding joint. When the peak current and pulse frequency is increased, the tensile strength is relatively increased. However, it is also seen that the base current is indirectly affecting the tensile properties of the welds. An increase in base current has inverse effect on tensile strength of the joint. Hence, in this work the influence of pulsating current on tensile behaviour of weldment have been studied.

S Kumar[5] studied welding possibility for higher thickness plates by TIG welding. Al plates with thickness varying 3-5mm were used for this purpose. The welding parameters were in the range (48-112) A and 
gas flow rate (7-15) lit/min. Shear strength of weld metal was found less than parent metal. From the analysis of photomicrograph of welded specimen it has been found that, weld deposits are form co-axial dendrite microstructure towards the fusion line and tensile fracture occur near to fusion line of weld deposit.

P kumar, SH Mankar, CK Datta[6] demonstrated the increase of mechanical properties and effective optimization of pulsed GTAW process parameters on aluminium alloy 6061. Welding was done with input parameters as base current (80-110) A, pulse frequency (50-125) HZ and pulse duty cycle (30-75) \%. Taguchi method was employed to calculate experimental structure and to study process optimization parameters on mechanical properties of the joints. Result of the experiment showed that pulse current, base current, pulse duty cycle and frequency plays significant role on microstructure and mechanical properties of weld, but pulse current plays the greater role i.e. $52.55 \%$. In this investigation, pulse current of $120 \mathrm{~A}$, background current of $80 \mathrm{~A}$, pulse frequency of $50 \mathrm{~Hz}$ and pulse duty cycle of $75 \%$ resulted in the maximum values of mechanical properties.

CHEN Yan Bin[7] studied the effect of welding parameters on mechanical properties of double sided TIG welded aluminium alloy. Experiment was performed on aluminium plate of dimensions (150x50x4) mm. The experimental result showed that mechanical properties and microstructure has greatly influenced by the cross sectional shape of the welding joint. The symmetrical cross section possesses a relatively $91 \%$ higher tensile strength and 58\% more elongation than the base metal. Lower hardness of fusion zone make it weakest area in the tensile test to fracture. The mechanical properties of joints are decreased due to loss of magnesium element.

A Kumar, S Sundarrajan[8] worked towards improvement of mechanical behaviour of AA5456 aluminium alloy welds with pulsed TIG welding process. The effect of welding current, welding speed and frequency on mechanical properties such as ultimate tensile strength (UTS), yield strength, hardness and percent elongation of AA5456 aluminium alloy weldments have been studied. The effect of planishing on mechanical properties was also studied and observed that there was improvement in mechanical properties. It is observed that, there is $10-15 \%$ enhancement in mechanical properties after planishing. This is due to fact that, internal stresses are relieved or redistributed in the weld.

Liu[9] did an analysis on mechanical properties, microstructure and micro hardness for the Li-Mg composite plates carried by TIG welding. A plate with dimension $(110 \times 10 \times 2) \mathrm{mm}$ was used with welding parameters as welding speed $30 \mathrm{~mm} / \mathrm{min}$, gas flow rate $13 \mathrm{lit} / \mathrm{min}$ and welding current $80 \mathrm{~A}$. The micro hardness near the fusion zone at Mg-Li composite side increased from weld metal to fusion zone and the peak value appeared near the boundary between fusion zone and $\mathrm{Mg}-\mathrm{Li}$ composite.

\section{CONCLUSION}

Literature survey reveals that a lot of work has been done on TIG welding of aluminium alloys. The research work has been found in literature for TIG welding of aluminium alloys and based on past work the following conclusions are drawn:

- Welding speed, welding current, welding voltage, electrode diameter and electrode gap, work piece material, shielding gas etc. are important process parameters for TIG welding.

- Out of the listed parameters welding current, gas flow rate and welding speed play a viatl role to perform precise and uniform welding of aluminium alloys.

- The range and selection of parameters depend upon type of material, strength required and specifications of welding machine used.

- Welding strength and welding profile is greatly influenced by selection of welding material and welding technique.

- For better strength and cleanliness in TIG welding of aluminium, AC power source is mostly preferred.

- Design of experiment can be determined by Taguchi method, Response Surface Technology and full factorial design.

- Minitab software is an important application for the evaluation of result.

- Microstructure investigation at different zones of weldment gives an comparative outcome between TIG welding and base material to differentiate the effect of temperature distribution. 
- UTM and Impact Testing Machine can be used for Tensile and Impact testing of TIG welded joints.

- Welding defects can be eliminated by proper welding precautions and controlling the different welding parameters.

- Automation of TIG welding process can make it more useful and precise. It can help to achieve faster welding speed, less distortion and even thin welding sheets can be easily welded with less skill required.

\section{REFERENCES}

[1] Palani PK, Saju M (2013). Optimization of process parameters for TIG welding of Aluminium-65032. International Journal of Engineering Research and Applications,Vol. 3, 230-236.

[2] Indira Rani (2012). Effect of Pulsed Current TIG Welding Parameters on Mechanical Properties of J-Joint Strength of AA6351. The International Journal of Engineering and Science (IJES), 1(1), 2319-1805.

[3] N Karunakaran, V Balasubramanian (2010). Effect of pulsed current on gas tungsten arc welded Aluminum alloy joints. Journals of Science Direct (SP), 21, 278-286.

[4] ST Kumar, V Balasubramanian V, MY Sanavullah (2006). Influences of pulsed current tungsten inert gas welding parameters on the tensile properties of AA 6061 aluminium alloy. Journals of Science Direct (SP), 28, 2080-2092.

[5] S Kumar (2010). Experimental investigation on pulsed TIG welding of aluminium plate. Advanced Engineering Technology, 1(2), 200-211.

[6] P Kumar, SH Mankar, CK Datta (2011). Process parameters optimization of aluminium alloy 6061 with pulsedGas tungsten arc welding. International journal of manufacturing technology and industrial engineering, Vol. 2, 49-54.

[7] CHEN Yan-bin, MIAO Yu (2008). Joint performance of laser-TIG double-side welded 5A06. Journals of Science Direct (SP), 19, 2631.

[8] A Kumar, S Sundarrajan (2008). Optimization of pulsed TIG welding process parameters on mechanical properties of AA 5456 Aluminum alloy weldments. Journals of Science Direct (SP), 30, 188-1297.

[9] LIU Xu-hel, GU Shi-hai1, WU Rui-zhi, LENG Xue-song, YAN Jiu-chun, ZHANG Mi-li, (2011). Microstructure andmechanical properties of Mg-Li alloy after TIG welding. Journals of Science Direct (SP), 477-481.

[10] LSingh (2013). An Evaluation of TIG Welding Parametric Influenceon Tensile Strength of 5083 Aluminium Alloy. International Journal of Mechanical, Aerospace, Industrial, Mechatronic and Manufacturing Engineering, Vol. 7, 1262-65. 